\title{
LC-MS method development for the quantitation of potential genotoxic impurity 2-Methyl-6-nitro aniline in Telmisartan API
}

\author{
Duvvuri Suryakala, Sivakumar Susarla*, Bandlamudi Mallikarjuna Rao
}

GITAM (Deemed to be University), Visakhapatnam, Andhra Pradesh, India.

\section{ARTICLE INFO \\ Received on: 06/11/2019 \\ Accepted on: 19/01/2020 \\ Available online: 06/05/2020}

\author{
Key words: \\ 2-Methyl-6-nitro aniline, \\ Telmisartan, Genotoxic \\ impurities, selected Ion \\ Monitoring (SIM), ICH \\ guidelines.
}

\begin{abstract}
Current work discloses the sensitive LC-MS/MS method development for the trace level determination of genotoxic impurity 2-Methyl-6-nitro aniline in Telmisartan. 2-Methyl-6-nitro aniline was determined by LC-MS/MS method in selected ion monitoring mode using LiChrospher RP-18 $(100 \times 4.6 \mathrm{~mm}) 5.0 \mu \mathrm{m}$ column. Gradient technique was applied for the elution of analytes using acetonitrile (mobile phase $\mathrm{A}$ ) and $0.01 \mathrm{M}$ ammonium acetate buffer (mobile phase $\mathrm{B}$ ) in different ratios. The gradient program $(\mathrm{T} / \% \mathrm{~B})$ was set as $0 / 5,2.50 / 15,5.00 / 30,10.00 / 50,15.00 / 95$, and 20.00/95. Developed method was validated as per International Conference on Harmonization guidelines. The limit of detection and limit of quantitation values found for 2-Methyl-6-nitro aniline were 0.05 and $0.1 \mu \mathrm{g} / \mathrm{ml}$. The developed method serves as an upright tool in quality control for quantitation of 2-Methyl-6-nitro aniline impurity at trace levels in Telmisartan.
\end{abstract}

\section{INTRODUCTION}

Telmisartan (Fig. 1a), is an important antihypertensive drug of the Angiotensin-II receptor blockers category. It is an efficient antagonist to angiotensin-II, which is a potent vasoconstrictor for both arteries and veins. As a result, the arteries and veins enlarge and blood pressure falls. It is also used for reducing the risk of heart attack, stroke, or death from cardiovascular causes (Lindholm et al., 2002; Sharma et al., 2002; Young et al., 2004). It is also producing a beneficial protective effect against vascular and renal damage instigated in diabetes and cardiovascular diseases, due to its arteriolar and venous dilation capability (Benson et al., 2004; Yusuf et al., 2008).

Since past decade impurities, especially genotoxic impurities' analysis and control strategies development in the final products became an epicenter in the pharmaceuticals and regulatory authorities. Active pharmaceutical Ingredients susceptible to comprise different impurities that may arise from

"Corresponding Author

Sivakumar Susarla, GITAM (Deemed to be University), Visakhapatnam, Andhra Pradesh, India. E-mail: shivakumarsdoer@gmail.com starting materials, reagents employed for the synthesis and by products in the synthetic process. Different reactants will be meticulously selected based on their reactivity in the synthesis of the drugs to achieve the optimum yields of end products. However, this same reactivity of the reactants could result in genotoxicity if any unreacted material left with the final product as an impurity, which makes these impurities to consider critically eliminating them from the final drug product (Pierson et al., 2009). Often different synthetic process related modifications are employed to remove these impurities, yet it became impossible to completely eliminate the impurities from the final drug substances. According to the guidance of drug regulatory authorities, it is crucial to regulate the level of genotoxic impurities in the drug substances based on the daily dose (Miller et al., 1977).

Aromatic amines are generally employed in the synthetic process as building blocks and are categorized as potentially genotoxic impurities (PGIs) in pharmaceuticals. Inherently aromatic amines genotoxicity is not owing to their reactivity but due to the generation of nitrenium ion $\left(\mathrm{Ar}-\mathrm{N}^{+} \mathrm{H}\right)$ by the oxidative metabolic reactions, which is considered to be the active genotoxin that binds to DNA (Snodin et al., 2010). Reports by various research groups suggest that PGIs are carcinogens in rats and mice that bring to induce genetic mutations or chromosomal aberrations. 


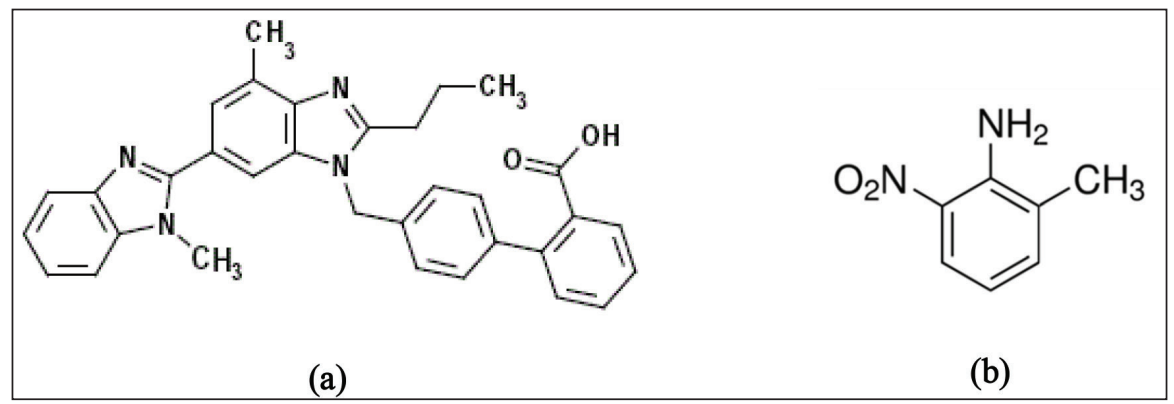

Figure 1. (a) Telmisartan. (b) 2 - Methyl- 6 -nitro aniline.

Aryl amines possess the regulatory limit of intake at $1.5 \mu \mathrm{g}$ /day (Kroes et al., 2004). A few synthetic processes have been reported for the Telmisartan which utilize the genotoxic substances as starting materials as well as intermediates. 2-Methyl-6-nitro aniline (Fig. 1b) is a potentially genotoxic in nature and it is an intermediate in the synthesis of Telmisartan generated from the methylation of o-nitroaniline with dimethyl sulfate (Szekely et al., 2015).

Regulatory authorities considered control of genotoxic impurities with utmost importance. European Medicines Agency's (EMEA) Committee for Medicinal products for Human use has issued guidelines concerning limits of genotoxic impurities (EMEA, 2006). In 2008, regarding the genotoxic and carcinogenic impurities in Active Pharmaceutical Ingredients (API), a draft of guidelines also outlined by US FDA. It consists of the different various routes to mitigate the potential lifetime cancer risk in patients with exposure to genotoxic impurities. Based on the current regulatory guidance for genotoxic impurities, analytical methods should be developed to meet the required limit of $1.5 \mu \mathrm{g} /$ day daily intake of individual impurity (CDER, 2008).

In the purview of the importance of the determination of genotoxic impurities in pharmaceuticals, an attempt was made to develop the sensitive LC-MS/MS method to determine the 2-Methyl-6-nitro aniline in very low levels in Telmisartan as there were no previous reports available, particularly regarding the analysis of 2-Methyl-6-nitro aniline in Telmisartan drug substance.

\section{EXPERIMENTAL}

\section{Materials}

2-Methyl-6-nitro aniline was procured from Sigma Aldrich, Bangalore, India. Analytical grade ammonium acetate and acetonitrile were purchased from Merck, India. Telmisartan sample was procured from Triveni Pharma, India.

\section{Chromatographic conditions}

The chromatographic system used was Shimadzu LCMS 8040. The analytical column was LiChrospher RP-18 (100 $\times 4.6 \mathrm{~mm}) 5.0 \mu \mathrm{m}$. Gradient elution mode was applied for the operation and the mobile phase A composed of $0.01 \mathrm{M}$ ammonium acetate buffer and mobile phase $\mathrm{B}$ is acetonitrile solvent. The gradient program $(\mathrm{T} / \% \mathrm{~B})$ was set as $0 / 5,2.50 / 5,7.00 / 50,12.00 / 70$, $18.00 / 95,21.00 / 95$, and 25.00/95. The flow rate adjusted to $1.0 \mathrm{ml} /$ minute for chromatography and the flow rate split down to 0.2 $\mathrm{ml} /$ minute in to the MS source. $20 \mu \mathrm{l}$ of analyte solution injected to column and column oven temperature was maintained at $40^{\circ} \mathrm{C}$. Instrument operation, data collection, and processing were done by LC-MS Lab Solutions.

\section{Mass spectrometer conditions}

Mass determination in selective ion monitoring (SIM) mode with positive ion electrospray ionization method was employed for the quantification of 2-Methyl-6-nitro aniline in drug substance. The analyte, 2-Methyl-6-nitro aniline was monitored with its molecular ion $\left[\mathrm{M}+\mathrm{NH}_{4}\right]^{+} \mathrm{m} / \mathrm{z}$ at 170 . The ion spray voltage $(V)$, entrance potential, and delustering potential were kept as $5,500,10$, and $46 \mathrm{~V}$, respectively. The curtain gas flow (psi), ion source gas 1 and ion source gas 2 nebulization pressure (psi) were maintained as 20,25, and 30, respectively. Venting was done using valco valve (Valco Instruments Co. Inc., VICI AG International). Venting was given from 8 to 14 minutes.

\section{Validation study}

ICH guidelines were followed for the validation of the developed LC-MS/MS method for the determination of 2-Methyl6-nitro aniline in Telmisartan ( $\mathrm{ICH}, 2005)$. By analyzing the six concentrations of analyte from 0.05 to $0.76 \mu \mathrm{g} / \mathrm{ml}$ (with respect to sample concentration of $20 \mathrm{mg} / \mathrm{ml}$ ), linearity of the method was established. Slope, intercept and regression coefficient were determined from the least square linear regression analysis. Six repetitive injections of Standard solution were employed to establish the system precision of the mass spectrometric response. LOQ and LOD were determined via exhibiting precision, by running six replicate injections of analyte in lower concentrations. The LOQ and LOD were calculated on the basis of the lowest concentration of compound that gives \%relative standard deviation $(\% \mathrm{RSD})<10$ (for LOQ) and \%RSD $<15$ (for LOD). The method precision was evaluated by spiking each analyte and determining the $\%$ RSD. The accuracy was determined by spiking the known amount of analyte with known amount of sample in six different volumetric flasks and it was calculated after making corrections for the amount pre-existed in the sample. Stability of analytes in sample solution was done by analyzing spiked sample solution at different time intervals at room temperature.

\section{Standard solution preparation}

Stock solution having concentration of $3.8 \mathrm{mg} / \mathrm{ml}$ of 2-Methyl-6-nitro aniline was prepared by dissolving it in 
acetonitrile. From the stock solution, diluted stock solution of 0.38 $\mathrm{mg} / \mathrm{ml}$ concentration was prepared by the dilution of $1 \mathrm{ml}$ of the $3.8 \mathrm{mg} / \mathrm{ml}$ solution to $10 \mathrm{ml}$ with acetonitrile. Prior to the injection into analytical system, from this diluted stock solution, the working standard solution of $0.38 \mu \mathrm{g} / \mathrm{ml}$ strength which is equivalent to the $18.75 \mathrm{ppm}$ with respect to the sample concentration of $20 \mathrm{mg} / \mathrm{ml}$ was prepared by the serial dilution in acetonitrile.

\section{Sample preparation}

Telmisartan sample solution of $20 \mathrm{mg} / \mathrm{ml}$ concentration was prepared before injection into system by dissolving about 20 mg of the drug substance with solvent in a HPLC vial.

\section{RESULTS AND DISCUSSION}

\section{Optimization of sample preparation}

Analytical method stability, sensitivity is affected by the sample preparation in trace level analysis of Genotoxic Impurities in a drug substance. Different diluents, such as acetonitrile, methanol, and combination of these diluents with water, were employed to achieve the efficient extraction and optimum response. Both the solvents produced satisfactory solubilization capacity for the analyte and drug substances. Therefore, acetonitrile was chosen finally as it provides better analyte response, proper peak shapes, and good recovery levels.

\section{Optimization of chromatographic conditions}

Various columns like Inertsil ODS C18, Atlantis T3 and LiChrospher 100 RP-18 of different dimensions were evaluated. Inertsil ODS C18 and Atlantis T3 columns were found to be not suitable, since the observance of low resolution and improper analyte response. Satisfactory response for the analyte 2-Methyl-6-nitro aniline and good resolution between analyte and Telmisartan were achieved on the LiChrospher 100 RP-18 column of dimensions $100 \mathrm{~mm} \times 4.6 \mathrm{~mm}$ internal diameter, $5.0 \mu \mathrm{m}$. Both, the isocratic and gradient elution modes employed during the method development. Diverse composition of mobile phase using $0.1 \%$ formic acid $0.1 \%$ acetic acid, ammonium formate, and ammonium acetate with acetonitrile and methanol were studied. Isocratic elution given unfavorable results during the method development with peak resolution and peak response for both, the analyte and Telmisartan. Decent response and separation were noticed with the combination of ammonium acetate buffer and acetonitrile in gradient elution mode. To avoid any shift in retention time, the column was thermo-stated at $40^{\circ} \mathrm{C}$ and 1.0 $\mathrm{ml} /$ minute of mobile phase flow rate was maintained. The flow rate was reduced to $0.2 \mathrm{ml} /$ minute by utilizing a splitter prior to the electrospray ionization. Retention time of 2-Methyl-6-nitro aniline was observed to be about 5.3 minutes.

Telmisartan peak eluted at around 11 minutes. Only the analyte, 2-Methyl-6-nitro aniline peak was permitted enter the mass detector with the help of a switching valco valve that executed the venting of drug substance peak. This technique enables the method development process to analyze the peak of interest and also avoids the matrix effect due to high concentration of drug substance.

\section{Optimization of mass spectrometric parameters}

Detection method is crucial for the development of Chromatographic technique as it directly related to the identification and quantitation of the analytes. Relatively, due to the greater sensitivity and specificity offered by the mass spectrometric detection, LC-MS/MS method was chosen over HPLC-UV for the trace analysis of 2-Methyl-6-nitro aniline and the analysis was executed in SIM mode which further increased the specificity of the determination. 2-Methyl-6-nitro aniline ion mass peak was seen at 170.2 corresponding to $[\mathrm{M}+18]^{+}=\left[\mathrm{M}+\mathrm{NH}_{4}\right]^{+}$. The LC-MS - SIM chromatograms are shown in Figures 2 and 3.

\section{Validation of method}

The newly developed LC-MS/MS method's validation was performed according to the ICH guidelines in relation to the analytical parameters such as specificity, accuracy, linearity, limit

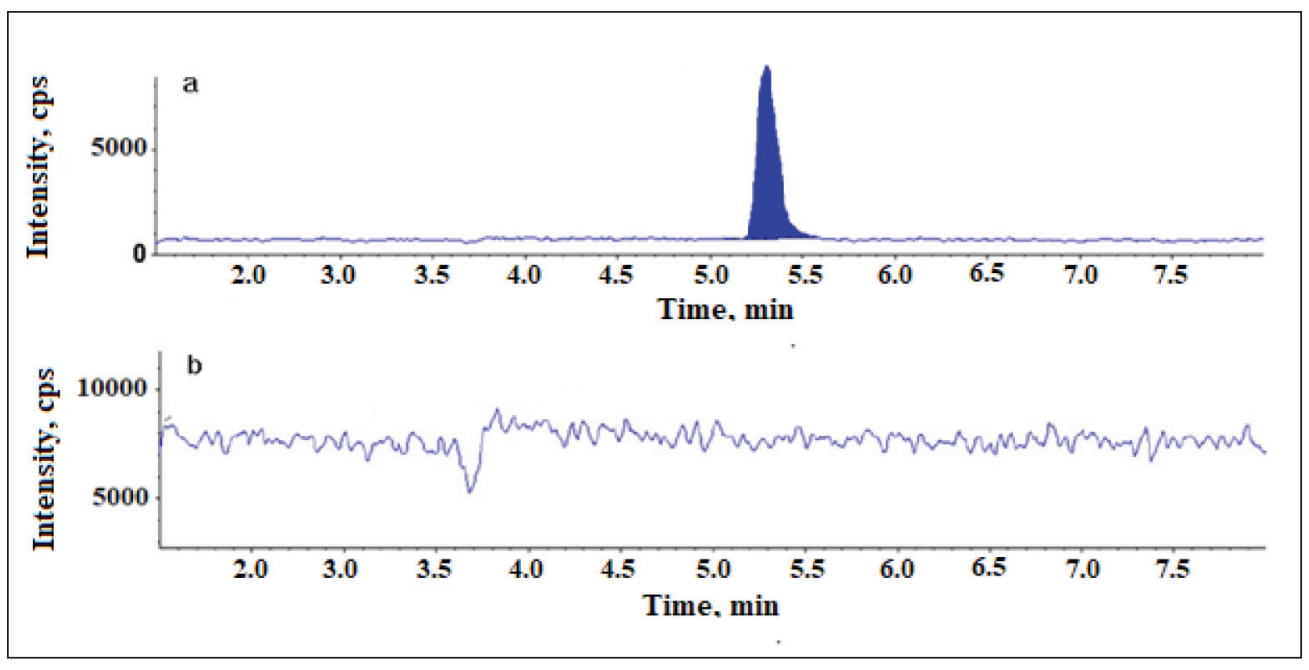

Figure 2. Chromatograms of 2-Methyl-6-nitro aniline using SIM scan. (a) Chromatogram of blank and (b) chromatogram of Telmisartan sample spiked with 2-Methyl-6-nitro aniline at $0.38 \mu \mathrm{g} / \mathrm{ml}$. 


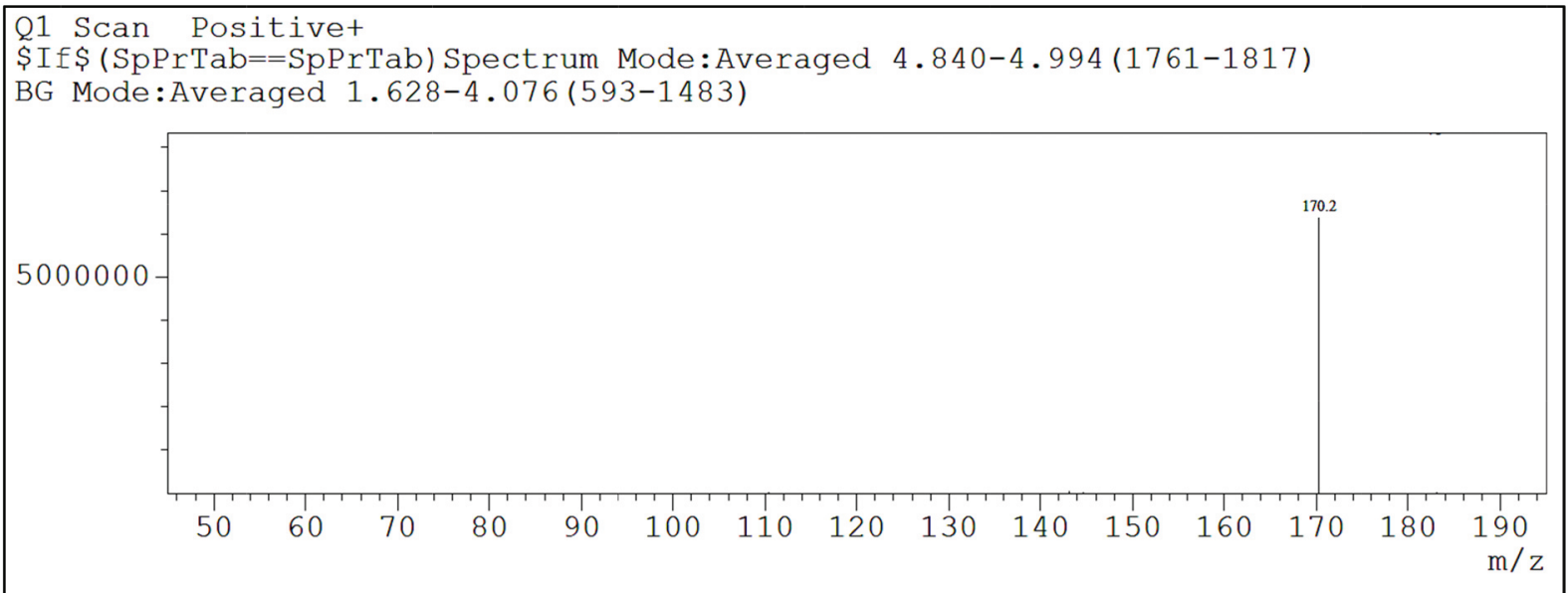

Figure 3. SIM Chromatogram of 2-Methyl-6-nitro aniline.

Table 1. Linearity of 2-Methyl-6-nitro aniline.

\begin{tabular}{|c|c|c|}
\hline \multirow{2}{*}{ S. No } & \multicolumn{2}{|c|}{ 2-Methyl-6-nitro aniline } \\
\hline & Concentration $\mu \mathrm{g} / \mathrm{ml}$ & Area \\
\hline 1 & 0.05 & 1,686 \\
\hline 2 & 0.1 & 3,167 \\
\hline 3 & 0.2 & 8,641 \\
\hline 4 & 0.38 & 18,599 \\
\hline 5 & 0.6 & 34,141 \\
\hline 6 & 0.76 & 43,626 \\
\hline Slope & \multicolumn{2}{|c|}{173,689} \\
\hline Intercept & \multicolumn{2}{|c|}{72.66} \\
\hline Correlation Coefficient & \multicolumn{2}{|c|}{0.9987} \\
\hline
\end{tabular}

of detection (LOD), limit of quantitation (LOQ), precision, and robustness in order to demonstrate the feasibility of the method.

\section{Specificity}

Specificity of the developed LC-MS/MS method for the analyte response at specification level was indicated by the retention of the 2-Methyl-6-nitro aniline at the time around 5.5 and the analyte response for 2-Methyl-6-nitro aniline in SIM mode at $m / z\left[\mathrm{M}+\mathrm{NH}_{4}\right]-170.2$ on mass spectrum.

\section{Limit of quantification (LOD) and detection (LOQ)}

The LOD and LOQ were calculated from $\mathrm{S} / \mathrm{N}$ ratio data generated from six injections of 2-Methyl-6-nitro aniline with respect to sample concentration of $20 \mathrm{mg} / \mathrm{ml}$. The results disclosed in Table 2. The LOD and LOQ values observed for 2-Methyl-6nitro aniline were 0.05 and $0.1 \mu \mathrm{g} / \mathrm{ml}$.

\section{Linearity}

The linearity of method in terms of mass spectrometric response with respect to concentration of analyte was demonstrated by a six-point calibration graph between 0.05 and $0.76(0.05-0.76$ ppm, corresponding to the concentration of 20 of Telmisartan). Correlation coefficients for all analytes were $>0.998$. Linearity results enumerated in Table 1. This indicates the sensitivity range of the proposed method and linearity results supports that
Table 2. LOD, LOQ precision.

\begin{tabular}{ccc}
\hline \multirow{2}{*}{ Injection ID } & \multicolumn{2}{c}{ 2-Methyl-6-nitro aniline } \\
\cline { 2 - 3 } & LOD & LOQ \\
\hline 1 & 894 & 1,786 \\
2 & 886 & 1,699 \\
3 & 899 & 1,756 \\
4 & 879 & 1,776 \\
5 & 880 & 1,790 \\
6 & 894 & 1,850 \\
Mean & 888.6666667 & $1,776.166667$ \\
$\mathrm{SD}$ & 7.520342782 & 44.90885832 \\
$\% \mathrm{RSD}$ & 0.846250125 & 2.528414656 \\
$\mathrm{Conc}(\mu \mathrm{g} / \mathrm{ml})$ & 0.05 & 0.1 \\
\hline
\end{tabular}

Table 3. System precision.

\begin{tabular}{cc}
\hline Injection ID & 2-Methyl-6-nitro aniline \\
\hline 1 & 8,584 \\
2 & 8,641 \\
3 & 8,709 \\
4 & 8,682 \\
5 & 8,751 \\
6 & 8,789 \\
Mean & $8,692.667$ \\
SD & 67.751 \\
$\%$ RSD & 0.779 \\
$95 \%$ Confidence Interval & \pm 102.5 \\
\hline
\end{tabular}

the developed method can analyze the 2-Methyl-6-nitro aniline genotoxic impurity at the specified requirement level of $1.5 \mu \mathrm{g} /$ day, that is, $0.38 \mu \mathrm{g} / \mathrm{ml}$ strength which is equivalent to the 18.75 ppm with respect to the sample concentration of $20 \mathrm{mg} / \mathrm{ml}$.

Precision

The precision of the methods was checked by injecting $0.05 \mu \mathrm{g} / \mathrm{ml}$ solution for six times. The values of relative standard 
deviations (RSDs) for the areas of each 2-Methyl-6-nitro aniline were calculated. The $\%$ RSD was found to be below $4 \%$ for both the analytes in system precision and the data were enumerated in Table 3.

\section{Robustness}

By demonstrating the resolution greater than 2.0 between analyte and drug substance, robustness of the method was ensured when column temperature $\left( \pm 5^{\circ} \mathrm{C}\right)$, organic solvent ratio in both mobile phases $\mathrm{A}$ and $\mathrm{B}( \pm 2 \%)$, and mobile phase flow rate $( \pm 0.2$ $\mathrm{ml} /$ minute), were deliberately varied.

\section{CONCLUSION}

In conclusion, a cost-effective, direct, accurate, and sensitive tandem mass spectrometric method was developed for screening and quantification of 2-Methyl-6-nitro aniline in the Telmisartan drug substances. SIM mode relatively provided better selectivity and sensitivity for the screening and quantitation of the analyte. SIM mode consents radically discounts or eliminates the matrix effects that restricts the accuracy and LOD and LOQ levels. The method is advantageous owing to its improved sensitivity and simpler sample preparation technique to those formerly reported methods. This method can be further studied for its application to other drug substances.

\section{FUNDING}

None.

\section{CONFLICT OF INTEREST}

The authors declare that there is no conflicts of interest.

\section{REFERENCES}

Benson SC, Pershad Singh HA, Ho CI, Chittiboyina C, Desai P, Praven M, Qi N, Wang J, Avery MA, Kurtz TW. Identification of telmisartan as a unique angiotensin II receptor antagonist with selective PPAR gammamodulating activity. Hypertension, 2004; 43:993-1002.

EMEA. Guideline on the Limits of Genotoxic Impurities, Committee for Medicinal Products for Human Use (CHMP), European Medicines Agency (EMEA), London, 28 June, 2006 (CPMP/SWP/5199/02, EMEA/CHMP/QWP/251344/2006)

Genotoxic and carcinogenic impurities in drug substances and products: recommended approaches. U.S. Department of Health and Human Services, Food and Drug Administration, Centre for Drug Evaluation and Research (CDER), Silver Spring, MD, December 2008.

ICH Guideline Q2 (R1). Validation of analytical procedures: text and methodology. ICH, Switzerland, 2005. Available via http://www. ich.org/file admin/ Public_Web_Site/ICH_Products/Guidelines/Quality/ Q2_R1/Step4/Q2_R1_Guideline.pdf (online)
Kroes R, Renwick AG, Cheeseman M, Kleiner J, Mangelsdorf I. Structure-based thresholds of toxicological concern (TTC): guidance for application to substances present at low levels in the diet. Food Chem Toxicol, 2004; 42:65-83.

Lindholm LH, Ibsen H, Dahlof B, Devereux RB, Beevers G, DeFaire U, Fyhrquist F, Julius S, Kjeldsen SE, Kristiansson K, Lederballe Pedersen O, Nieminen MS, Omvik P, Oparil S, Wedel S, Anurup P, Edelman. Cardiovascular morbidity and mortality in patients with diabetes in the Losartan Intervention for Endpoint reduction in hypertension study (LIFE): a randomised trial against atenolol. Lancet, 2002; 359:1004-10.

Miller JA, Miller EC. Ultimate chemical carcinogen as reactive mutagenic electrophiles. In Origin of Human Cancers. Cold Spring Harbor Laboratory Press, Cold Spring Harbor, NY, pp 605-7, 1977.

Pierson DA, Olsen BA, Robbins DK, DeVries KM, Varie DL. Approaches to assessment, testing decisions, and analytical determination of genotoxic impurities in drug substances. Organic Process Res Dev, 2009; $13: 285-91$.

Sharma M, Janke J, Gorzelniak K, Engeli S, Luft FC. Angiotensin blockade prevents type 2 diabetes by formation of fat cells. Hypertension, 2002; 40:609-11.

Snodin DJ. Genotoxic impurities: from structural alerts to qualification. Org Proc Res Dev, 2010; 14:960-76.

Szekely G, Amores de Sousa MC, Gil M, Castelo Ferreira F, Heggie W. Genotoxic impurities in pharmaceutical manufacturing: sources, regulations, and mitigation. Chem Rev, 2015; 115(16):8182-229.

Young JB, Dunlap ME, Pfeffer MA, Probstfield JL, Cohenolal A, Dietz R, Granger CB, Hradec J, Kuch J, Mc Kelvie RS, McMurray JJ, Michelson EL, Olofsson B, Ostergren J, Held P, Solomon SD, Yusuf S, Swedberg K. Mortality and morbidity reduction with candesartan in patients with chronic heart failure and left ventricular systolic dysfunction: results of the CHARM low-left ventricular ejection fraction trials. Circulation, 2004; 110:2618-26.

Yusuf S, Teo KK, Pogue J, Dyal L, Copland I, Schumacher $\mathrm{H}$, Dagenais G, Sleight P, Anderson C. Telmisartan, ramipril, or both in patients at high risk for vascular events. N Engl J Med, 2008; 358:1547-59.

\section{How to cite this article:}

Suryakala D, Susarla S, Rao BM. LC-MS method development for the quantitation of potential genotoxic impurity 2-Methyl6-nitro aniline in Telmisartan API. J Appl Pharm Sci, 2020; 10(05):092-096. 